\title{
Association among Serum Organochlorine Pesticide Residues, Glutathione S-Transferase M1 Genetic Polymorphism and Female Breast Cancer
}

\author{
Jun $\mathrm{Li}^{1,2^{*}}$, Shoufang $\mathrm{Jiang}^{2}$, Yongli Chang ${ }^{3}$, Zhong Guo ${ }^{4}$, Sanqiao $\mathrm{Yao}^{2}$, Juxiang Yuan ${ }^{2}$, Guoli $\mathrm{Li}^{5}$ \\ ${ }^{1}$ Medical College, Hubei Arts and Sciences University, Xiangyang, China \\ ${ }^{2}$ School of Public Health, Hebei Union University, Tangshan, China \\ ${ }^{3}$ Xingtai Medical Higher Junior College, Xingtai, China \\ ${ }^{4}$ Center for Disease Control and Prevention in Tangshan City, Tangshan, China \\ ${ }^{5}$ Center for Disease Control and Prevention in Yutian County, Tangshan, China \\ Email: ${ }^{*}$ junlits@163.com
}

Received November 29, 2012; revised December 31, 2012; accepted January 8, 2013

Copyright (C) 2013 Jun Li et al. This is an open access article distributed under the Creative Commons Attribution License, which permits unrestricted use, distribution, and reproduction in any medium, provided the original work is properly cited.

\begin{abstract}
Background: The purpose of this study was to evaluate the association among serum organochlorine pesticide residues, glutathione S-transferase M1 genetic polymorphism and female breast cancer. Methods: A 1:1 matched case-control study of 140 newly diagnosed breast cancer patients and 140 non-cancer female patients who consulted the five largest hospitals in the Tangshan city from September 2006 to October 2007. Results: The result showed higher risk of breast cancer among subjects with higher levels of serum DDT and $\mathrm{HCH}$ residue, the $O R$ was $3.18(95 \% \mathrm{CI}, 1.11-9.07)$ and $5.02\left(95 \% \mathrm{CI}, 1.64\right.$ - 16.56). The value of $O R_{e}$ associated with single environmental factor DDT high residues, and $O R_{g}$ associated with single GSTM1 deletion genotype were respectively $3.86(1.20-12.47)$ and $1.34(0.36-5.08)$. The $O R_{e g}$ associated with combined action of two factors was $5.59(1.63-18.90)$, and the value of interaction parameters $(\gamma)$ equaled 1.24. The value of $O R_{e}$ associated with single environmental factor $\mathrm{HCH}$ higher residue and $O R_{g}$ associated with single GSTM1 deletion genotype were respectively $2.73(0.84-8.87)$ and $1.48(0.49-4.60)$. The value of $O R_{e g}$ associated with combined action of two factors was $3.87(1.18-12.68)$, and $\gamma$ equaled 1.38. Conclusion: The results indicated that breast cancer occurrence was the combined result of environmental and genetic factors. The concurrent action of GSTM1 deletion genotype and DDT/HCH enhanced the risk of breast cancer.
\end{abstract}

Keywords: Breast Cancer; DDT; HCH; Glutathione S-Transferase M1 (GSTM1); Endocrine Disruptors; Gene Polymorphism; Interaction

\section{Introduction}

Breast cancer is one of the most common malignant tumor in women, and becomes the female malignant tumor of the highest incidence, which is increasing with the most rapid rate all over the world. Up to now, the etiology of breast cancer is obscure. Breast cancer is one of reproduction-endocrine related tumor. All environmental and genetic factors which can disrupt anabolism and function of endocrine may increase the risk of breast cancer. Persistent environmental endocrine disruptors chemical (EDCs) can disrupt anabolism and function of endogenous hormone and the degree of disruption may depend on genetic polymorphism. Organochlorines pesti-

"Corresponding author. cides is a kind of persistent organic pollutants with a long period of residual and causes persistent environmental pollution. Organochlorine pesticides can interfere with estrogen levels and biological activity by affecting synthetic estrogen-metabolizing enzymes. The degree of interference may be relevant with the genetic polymorphism of metabolizing enzymes (glutathione S-transferases, GSTs). According to clinical observation, tendency was observed that the incidence rate of breast cancer was increasing year by year and the cases showed younger in age. A great quantity of pesticides and disinfectants were adopted to protect victims' health after Tangshan earthquake in 1976. About over 300 tons of organophosphorus pesticides, 84 tons of organochlorine pesticide DDT, and 416 tons of $\mathrm{HCH}$ were used in total 
[1]. However, there exists some established effects that DDT and $\mathrm{HCH}$ disturbed estrogen activity. In present study, a hospital-based 1:1 matched case-control study was conducted to analyze the interaction of environmental and genetic factors, that is to probe into the association among organochlorine pesticides residues, GSTM1 gene polymorphism and breast cancer, and to provide theory foundation for studying the etiology and primary prevention of breast cancer.

\section{Subjects and Methods}

\subsection{Subjects}

From September 2006 to October 2007, 140 women in 5 hospitals of Tangshan were invited to participate in the study. All of them had been living locally for over 10 years and were diagnosed as primary breast cancer by pathology. Those patients who were metastatic breast cancer, or had mental disorder, or were on ones' deathbed were excluded. Meanwhile the controls were collected matching with the cases by age ( \pm 2.5 years) and residence in the same hospitals. And the patients who had occupational exposure history, or other tumors, or endocrine correlated illnesses, or reproductive system diseases, or mental disorder were excluded. The participants were interviewed and filled in the questionnaires.

\subsection{Contents and Methods}

\subsubsection{Reagents and Apparatus}

Main reagents: $10 \times$ buffer, $\mathrm{MgCl}_{2}$, dNTPs (dATP, dGTP, dCTP, dTTP), Taq polymerase, EB, TBE, PCR Marker, Agarose, et al. (purchased from SINO-AMERICAN BIOTECHNOLOGY CO., LTD), DDT/HCH standards (NRCCRM), Anhydrous Sodium Sulfate (analytically pure), Concentrated sulphuric acid (analytically pure), Normal hexane.

Main apparatus: supercentrifuge with low temperature, PCR Thermal Cycler, electrophoresis apparatus, gelatin imaging image analyzer, $-20^{\circ} \mathrm{C}$ cryogenic refrigerator, GC-4000A gas chromatograph (with ${ }^{63} \mathrm{Ni}-\mathrm{ECD}$ detector, produced in Beijing City East and west Electronic Technology Institute).

\subsubsection{Detection of Serum Organochlorine Pesticides}

To collect $4 \mathrm{ml}$ bloods of 140 pairs of cases and controls, and $2 \mathrm{ml}$ serum after centrifugalization, reserved at $-20^{\circ} \mathrm{C}$. According to the methods of national standard GB/T 5009.19-2003 and improved sample handling [2], the levels of $\mathrm{HCH}$ and DDT were detected by gas chromatography (GC-ECD).

Appraisal standard of environmental exposure: According to percentile P50 of total $\mathrm{HCH}$ and total DDT residues in serum of the control group, two groups were divided into high and low residual group. The appraisal value of serum DDT totally is $15.013 \mu \mathrm{g} / \mathrm{L}$. High residue group is beyond the value, and low residue group is less than the value. So did the case of $\mathrm{HCH}$ and the appraisal value was $7.111 \mu \mathrm{g} / \mathrm{L}$. The values are established separately by the median of $\mathrm{DDT} / \mathrm{HCH}$ content of the controls.

\subsubsection{Determination of GSTM1 Genotype}

$4 \mathrm{ml}$ venous blood of all subjects anticoagulant by EDTA were collected and extracted DNA using salting out method. GSTM1 gene polymorphism was detected by Polymerase Chain Reaction (PCR) as reported previously [3]. GSTM1 primer was constructed and $\beta$-globin (268 bp) was as internal control respectively purchased from SBS Genetech Co., Ltd.

Genotype Determination: There existed two amplification fragments of $215 \mathrm{bp}$ and $268 \mathrm{bp}$ when the genotype of GSM1 was nondeletion. As unequal crossover happened between homologous chromosomes, it would lead to the loss of bases of $15 \mathrm{~kb}$ which was called deletion genotype. Any amplification fragment won't appear but one stripe of $268 \mathrm{bp}$ internal control when the genotype of GSM1 was deletion (as Figure 1 showed).

\subsubsection{Statistical Analysis}

A data base was established in Excel worksheet and analyzed with SAS 6.12 software. The relation between GSTM1 gene polymorphism and breast cancer was analyzed using $\chi^{2}$ test. Conditional logistic regression model were applied to elucidate the impact of organochlorine pesticide on the progress of breast cancer. The interaction of GSTM1 gene polymorphism and organochlorine pesticide were analyzed using 2 type Interaction Model [4]. According to interaction coefficient $\left(\gamma, \gamma=\beta_{e g} \beta_{e}\right)$, whether the interaction existed or not and which type it were judged. Judging criterion 1: $O R_{e g}=O R_{e} \times O R_{g}$, it was multiplication model; $O R_{e g}>O R_{e} \times O R_{g}$, it showed super-multiplication model; $O R_{e g}<O R_{e} \times O R_{g}$, it appeared hypomultiplication model; $O R_{e g}=O R_{e}+O R_{g}-1$,

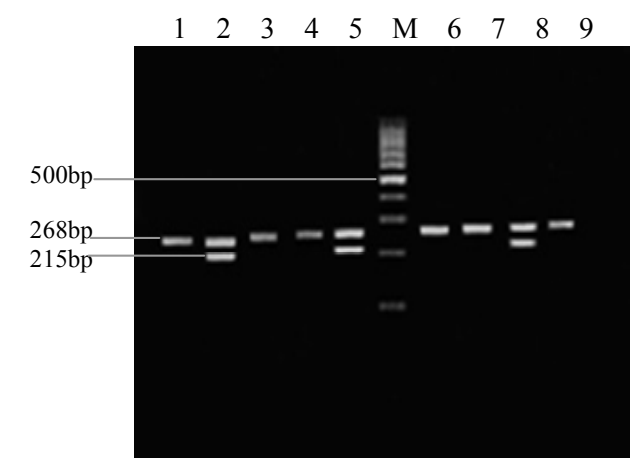

Figure 1. 1-9 was the detection results of GSTM1 gene polymorphism after PCR amplification. M: PCR Marker; 2, 5, 8: GSTM1 non-deletion genotype; 1, 3, 4, 6, 7, 9: GSTM1 deletion genotype. 
it was adding model. Judging criterion 2: $\gamma>1$, it showed genetic factor had magnified the effect of environmental factor, which was positive interaction. $\gamma>1$, it indicated that genetic factor had weakened the effect of environmental factor, which was negative interaction. $\gamma<1$, it suggested that there was no interaction of genetic factor and environmental factor. When environmental factor was risk factor, $\beta_{e}>0$, and $\gamma<0$, it manifested that genetic factor had stronger protection effect.

\section{Results}

\subsection{Comparison of General Conditions between the Case and Control Groups}

Mean ages of the case and control groups were respectively $48.3 \pm 8.9(29.0-76.0)$ and $47.9 \pm 8.7$ (28.0 - 76.0) years old. The difference between two groups was not statistically significant $(\mathrm{t}=1.17, \mathrm{P}=0.243)$. The ages of the cases were mostly in the range of 40.0 - 50.0 years (58 cases, 41.4 percent). There was even five cases under 35 years old, which prompted the tendency that breast cancer had attacked many younger people. Occupation, degree of education and marital status of the two groups were also compared. The results showed that the differences were not statistically significant. So the data of the two groups was comparable.

\subsection{The Relationship of DDT/HCH Residues Level and Breast Cancer (See Tables 1 and 2)}

The DDT, $\mathrm{HCH}$ residue levels and breast cancer risk factors (number of abortion, estrogen use history and so on) were introduced the conditional logistic regression model. The results showed the risk of breast cancer in high serum total DDT residual group $(>15.013 \mu \mathrm{g} / \mathrm{L})$ is 3.18 multiple of low residual group $(\leq 15.013 \mu \mathrm{g} / \mathrm{L})$, the risk of breast cancer in high serum total $\mathrm{HCH}$ residual group $(>7.113 \mu \mathrm{g} / \mathrm{L})$ is 5.02 times of low residual group $(\leq 7.113 \mu \mathrm{g} / \mathrm{L})($ see Tables 1 and 2$)$.

\subsection{The Relation of GSTM1 Gene Polymorphism and Breast Cancer (See Table 3)}

Stratified analysis with GSTM1 deletion or non deletion and $\chi^{2}$ test were used, any relevancy between GSTM1 genotype and breast cancer were failed to find $[P=0.262$, $O R=1.44(0.76-2.71)]$.

\subsection{The Interaction of GSTM1 Gene Polymorphism and Serum Organochlorine Pesticide Residues (See Tables 4 and 5)}

As shown in Table 4, the value of $O R_{e}$ associated with
Tables 1. The relationship between DDT $(\mu \mathrm{g} / \mathrm{L})$ residues lever and breast cancer.

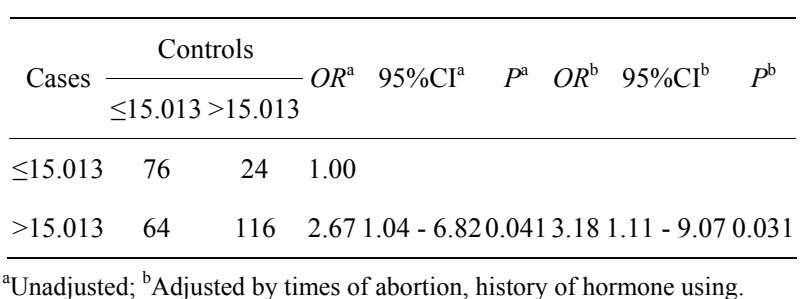

Tables 2. The relationship between $\mathrm{HCH}$ residues $(\mu \mathrm{g} / \mathrm{L})$ lever and breast cancer.

\begin{tabular}{|c|c|c|c|c|c|c|c|c|}
\hline Cases & & $\begin{array}{l}\text { rols } \\
7.111\end{array}$ & $O R^{\mathrm{a}}$ & $95 \% \mathrm{CI}^{\mathrm{a}}$ & $P^{\mathrm{a}}$ & $O R^{\mathrm{b}}$ & $95 \% \mathrm{CI}^{\mathrm{b}}$ & $P^{\mathrm{b}}$ \\
\hline$\leq 7.111$ & 60 & 20 & 1.00 & & & & & \\
\hline$>7.111$ & 80 & 120 & 4.00 & $1.50-10.66$ & 0.006 & 5.02 & $1.64-16.56$ & 0.005 \\
\hline
\end{tabular}

${ }^{\mathrm{a}}$ Unadjusted; ${ }^{\mathrm{b}}$ Adjusted by times of abortion, history of hormone using.

Table 3. The relation of GSTM1 gene polymorphism and breast cancer.

\begin{tabular}{cccccccc}
\hline \multirow{2}{*}{ Cases } & \multicolumn{2}{c}{ Controls } & & & & & \\
\cline { 2 - 3 } & $\begin{array}{c}\text { Non } \\
\text { deletion }\end{array}$ & deletion & & & & & \\
\hline $\begin{array}{c}\text { Non } \\
\text { deletion }\end{array}$ & 76 & 64 & 140 & 1.00 & & & \\
Deletion & 92 & 48 & 140 & 1.44 & $0.76-2.71$ & 1.256 & 0.262 \\
Total & 168 & 112 & 280 & & & & \\
\hline
\end{tabular}

Table 4. The interaction of GSTM1 gene polymorphism and serum DDT residues.

\begin{tabular}{|c|c|c|c|c|c|c|c|}
\hline $\begin{array}{c}\text { DDT } \\
\text { GSTM1 residues } \\
(\mu \mathrm{g} / \mathrm{L})\end{array}$ & $\begin{array}{l}\text { Cases } \\
(140)\end{array}$ & $\begin{array}{l}\text { Controls } \\
\text { (140) }\end{array}$ & $O R$ & $O R 95 \% \mathrm{CI}$ & $\beta \mathrm{e}$ & $\beta$ eg & $\gamma$ \\
\hline $\begin{array}{l}\text { Non } \\
\text { deletion }\end{array}$ & 318 & 40 & 1.00 & & 0.000 & & \\
\hline$\underset{\text { deletion }}{\text { Non }}>15.013$ & 52 & 44 & 3.860 .024 & $1.20-12.47$ & 1.39 & & \\
\hline Deletion $\leq 15.013$ & 22 & 30 & 1.340 .663 & $0.36-5.08$ & 0.00 & 0.30 & \\
\hline Deletion $>15.013$ & 48 & 26 & 5.560 .006 & $1.63-18.90$ & 1.39 & 1.72 & 1.24 \\
\hline
\end{tabular}

Table 5. The interaction of GSTM1 gene polymorphism and serum HCH residues.

\begin{tabular}{|c|c|c|c|c|c|c|}
\hline $\begin{array}{r}\mathrm{HCH} \\
\text { GSTM1 residues } \\
(\mu \mathrm{g} / \mathrm{L})\end{array}$ & $\begin{array}{l}\text { Cases } \\
(140)\end{array}$ & $\begin{array}{l}\text { Controls } \\
(140)\end{array}$ & $O R$ & $\mathrm{P}$ & OR $95 \% \mathrm{CI}$ & $\beta$ e $\beta$ eg $\gamma$ \\
\hline $\begin{array}{c}\text { Non } \\
\text { deletion }\end{array}$-7.111 & 22 & 38 & 1.00 & & & 0.00 \\
\hline $\begin{array}{c}\text { Non } \\
\text { deletion }\end{array}$ & 48 & 46 & 2.73 & 0.09 & $0.84-8.87$ & 0.98 \\
\hline Deletion $\leq 7.111$ & 28 & 32 & 1.48 & 0.495 & $0.48-4.60$ & $\begin{array}{lll}0.00 & 0.39\end{array}$ \\
\hline Deletion $>7.111$ & 42 & 24 & 3.87 & 0.026 & $1.18-12.68$ & $30.98 \quad 1.351 .38$ \\
\hline
\end{tabular}


single environmental factor DDT high residues was 3.86, $O R_{g}$ associated with single GSTM1 deletion genotype was 1.34 , and $O R_{e g}$ associated with combined action of the two factors was 5.56. The value of $\gamma$ equaled 1.24, suggested that GSTM1 deletion genotype had increased the effect of serum DDT residues. And the type of interaction was 2 type super-multiplication model.

As shown in Table 5, the value of $O R_{e}$ associated with single environmental factor $\mathrm{HCH}$ high residues was 2.73, $O R_{g}$ associated with single GSTM1 deletion genotype was 1.48 , and $O R_{e g}$ associated with the two factors together was 3.87. The value of $\gamma$ equaled 1.38, which manifested that GSTM1 deletion genotype had increased the effect of serum $\mathrm{HCH}$ residues. And the type of interaction was the hypo-multiply model.

\section{Discussion}

Organochlorine pesticides, a class of hydrocarbon compounds characterized by their cyclic structure, number and position of chlorine atoms, and low volatility, were widely used in agriculture and pest control after they were introduced in the 1940s. They include hexachlorocyclohexane $(\mathrm{HCH})$ isomers, DDT and its analogs, and cyclodienes. Organochlorine compounds degrade slowly, are lipid soluble, bioaccumulate in the food chain, and may be found in human adipose tissue, blood, and breast milk. Some organochlorine compounds have accumulated and persisted within the environment. As a result, measurable amounts can still be found in human tissue. Because of their nature of persistence in the environment, bioaccumulation in the food chain, and possible health effects, the US Environmental Protection Agency restricted and banned the use of most of organochlorine pesticides during the 1970s and 1980s. Although Organochlorine pesticides are rarely used in the United States today, measurable amounts of Organochlorine pesticides or their metabolites can still be found in human tissues in the United States. Moreover, Organochlorine pesticides continue to be heavily used in some developing countries, primarily for mosquito and malaria control. Thus, the health effects of Organochlorine exposure remain an important global public health concern $[5,6]$.

Because some organochlorine compounds act as estrogen agonists or antagonists within in vitro and experimental animal systems, a possible association of breast cancer risk with organochlorine exposure has been hypothesized and investigated deeply. Some of these compounds may have other adverse environmental or health effects. Levels in human tissues are positively associated with age, as a result of accumulation from the environment and historically higher levels of exposure. They can influence internal anabolic process of endogenous estro- gen. Although use of DDT and $\mathrm{HCH}$ has been banned in the China since the 1980s, a great amount of organochlorine pesticides were spraying after earth quake in 1976 year, which resided in the soil, water and air, resulting in the large environment pollution. This study implied that there were some relevance between total DDT and $\mathrm{HCH}$ residues and breast cancer. The higher risk of breast cancer among subjects with higher DDT and HCH residues were observed in this study, which was in accordance with some foreign researches [6-8]. Besides results from two studies suggested that a positive association between organochlorine compounds and breast cancer may be more evident in African-American women than in Caucasian women $[9,10]$. However, any relationship between the level of internal $\beta$-HCH level and breast cancer hadn't been confirmed by Lopez-Carrillo's study on Mexico women [11]. A large number of pesticides were once used widely in China, and the total DDT and $\mathrm{HCH}$ accumulated more than 3 times as much as other countries in the corresponding period [12]. From this perspective, internal researches in China would be more meaningful and persuasive.

Glutathione S-transferases (GSTs) belong to important II phase detoxifying enzyme family in vivo. GSTM1 gene is located at $1 \mathrm{p} 13.3$, coding GST- $\mu$ isozyme. GSTM1 deletion genotype can reduce the activity of GST- $\mu$ enzyme, or even lost. Some studies found that premenopausal female with GSTM1 deletion genotype had more increasing risk of breast cancer $[13,14]$. In a nested case-control study within the Nurses' Health Study, no association was found between the GSTM1 deletion and the development of incident breast cancer. The gene deletion polymorphism appeared to confer improved survival, however, and the null genotype was slightly more common among women with prevalent breast cancer $(58 \%)$ than among controls $(51 \%$; age-adjusted $O R=1.3 ; 95 \% \mathrm{CI}=0.9-1.9)$ [15]. There weren't correlation of GSTM1 deletion genotype and the development of breast cancer in this paper $(\mathrm{OR}=1.44$; $95 \% \mathrm{CI}=0.76-2.71)$.

Further interaction coefficient $\left(\gamma, \gamma=\beta_{e g} / \beta_{e}\right)$ was applied to discuss the interaction of GSTM1 deletion genotype and organochlorine pesticides and their impact on breast cancer. Our study supported the hypothesis that there were certain interactions between GSTM1 deletion genotype and DDT/HCH in the development of breast cancer. The valves of $\gamma$ were respectively 1.24 and 1.38 . The models of interactions showed separately super-multiply and hypo-multiply model, which indicated that breast cancer occurrence was the combined result of environmental and genetic factors. The concurrent action of GSTM1 deletion genotype and DDT/HCH enhanced the risk of breast cancer. 


\section{REFERENCES}

[1] Q. J. Zhou, Z. P. Wang and F. B. Chen, "Research on Community Revert and Social Problems of Earthquake Stricnken Area in Tangshan," Earthquake Publish Company, Beijing, 1997, pp. 398-401.

[2] J. Y. Li, D. S. Wu, F. Yang, H. Y. Zeng, F. M. Lei, W. D. Zhou, H. Li and P. Tao, "A Case-Control Study on Exposure of Serum Organochlorine Pesticide DDT, CYP1A1 Gene Polymorphism and Breast Cancer," Chinese Journal of Epidemiology, Vol. 27, No. 3, 2006, pp. 217-222.

[3] K. Chen, X. Y. Ma and K. Y. Yao, "A Case-Control Study on the Association among Glutathione S-Transferases, Gene Polymorphism, Smoking and Rectum and Colon Cancer," China Tumour Journal, Vol. 26, No. 11, 2004, pp. 645-648.

[4] M. J. Khoury and D. K. Wagener, "Epidemiological Evaluation of the Use of Genetics to Improve the Predictive Value of Disease Risk Factors," The American Journal of Human Genetics, Vol. 56, No. 4, 1995, pp. 835-844.

[5] E. E. Calle, H. Frumkin, S. J. Henley, D. A. Savitz and M. J. Thun, "Organochlorines and Breast Cancer Risk," $A$ Cancer Journal for Clinicians, Vol. 52, No. 5, 2002, pp. 301-309.

[6] A. Demers, P. Ayotte, J. Brisson, S. Dodin, J. Robert and E. Dewailly, "Risk and Aggressiveness of Breast Cancer in Relation to Plasma Organochlorine Concentrations," Cancer Epidemiology, Biomarkers \& Prevention, Vol. 9, No. 2, 2000, pp. 161-166.

[7] R. Isabelle, H. A. Mauricio, L. P. Eduardo, J. P. Weber and E. Dewailly, "Breast Cancer, Lactation History, and Serum Organochlorines," American Journal of Epidemiology, Vol. 152, No. 4, 2000, pp. 363-370. doi:10.1093/aje/152.4.363

[8] J. Y. Li, H. Li, F. M. Lei and D. S. Wu, "A Meta-Analysis on Relationship between DDE Contents in Body and
Human Breast Cancer," Modern Preventive Medicine, Vol. 32, No. 2, 2005, pp. 91-93, 110.

[9] N. Krieger, M. S. Wolff, R. A. Hiatt, et al., "Breast Cancer and Serum Organochlorines: A Prospective Study among White, Black, and Asian Women," Journal of the National Cancer Institute, Vol. 86, No. 8, 1994, pp. 589599. doi:10.1093/jnci/86.8.589

[10] R. Millikan, E. DeVoto, E. J. Duell, et al., "Dichlorodiphenyldichloroethene, Polychlorinated Biphenyls, and Breast Cancer among African-American and White Women in North," Cancer Epidemiology, Biomarkers \& Prevention, Vol. 9, No. 11, 2000, pp. 1233-1240.

[11] X. M. Hua and Z. J. Shan, "Analysis of Pesticides Production, Using Status and Impact Factors," Environmental Scientific Advance, Vol. 4, No. 2, 1996, pp. 33-45.

[12] S. K. Park, D. Kang, D. Y. Noh, K. M. Lee, S. U. Kim, J. Y. Choi, I. M. Choi, S. H Ahn, K. J. Choe, A. Hirvonen, P. T. Strickland and K. Y. Yoo, "Reproductive Factors, Glutathione S-Transferase M1 and T1 Genetic Polymorphism and Breast Cancer Risk," Breast Cancer Research and Treatment, Vol. 78, No. 1, 2003, pp. 89-96. doi:10.1023/A:1022113713226

[13] J. Y. Jiang, Y. B. Xiang, M. H. Tao and W. H. Xu, "The Research Advances on the Gene-Environment Interaction of Breast Cancer," Tumor, Vol. 31, No. 6, 2011, pp. 558564.

[14] X. H. Xu, L. Amy, B. Dailey, L. Evelyn, O. Talbott, et al., "Associations of Serum Concentrations of Organochlorine Pesticides with Breast Cancer and Prostate Cancer in US Adults," Environmental Health Perspectives, Vol. 118, No. 1, 2010, pp. 60-66.

[15] T. R. Rebbeck, "Molecular Epidemiology of the Human Glutathione S-Transferase Genotypes GSTM1 and GSTT1 in Cancer Susceptibility," Cancer Epidemiology, Biomarkers \& Prevention, Vol. 6, No. 9, 1997, pp. 733-743. 